\title{
MODERNIDAD, HISTORIA, LIBERTAD Y GRACIA. LO QUE ME HA ENSEÑADO (HASTA AHORA) VICO
}

\author{
Antonio Sabetta \\ (Universidad Pontificia Lateranense, Roma)
}

RESUMEN: Esta contribución evidencia algunos aspectos del pensamiento de Vico que han marcado al Autor: el rol de iniciador de una "diversa modernidad", la historia como único lugar para una "teología filosófica", y la relación entre libertad y providencia. Para el Autor el pensamiento viquiano se presenta antimonolítico, rico, compuesto y variado como para huir de toda reconducción dentro de estrecheces historiográficas fijas.

Palabras ClaVe: Vico, $350^{\circ}$ Aniversario, modernidad, historia, providencia, libertad, ontologismo, historia ideal eterna, De Antiquissima, A. Sabetta.

\section{Modernity, history, freedom and grace. What Vico has shown me (until now)}

ABSTRACT: This contribution highlights some aspects of Vico's thought that have marked the author: the role of initiator of a "diverse modernity", history as the only place for a "philosophical theology", and the relationship between freedom and providence. According to the Author, Viquian thought shows up as antimonolitic, rich, composed and varied, escaping any reconduction within fixed historiographic constraints.

KEYWORDS: Vico, $350^{\text {th }}$ Anniversary, modernity, history, providence, freedom, ontologism, eternal ideal history, De Antiquissima, A. Sabetta.

\section{Modernità, storia, libertà e gracia. Cì̀ che mi ha insegnato (sino ad ora) Vico}

RIASSUNTO: In questo contributo si evidenziano alcuni aspetti del pensiero di Vico che hanno profondamente segnato l'Autore: il ruolo di iniziatore di una "modernità altra", la storia come unico luogo per una "teologia filosofica" e il rapporto tra libertà e provvidenza. Per l'Autore, il pensiero vichiano appare antimonolitico, ricco, articolato e vario, tanto da sfuggire a qualsiasi tentativo di riconduzione entro limiti storiografici prestabiliti.

PAROLE CHIAVE: Vico, $350^{\circ}$ Anniversario, modernità, storia, provvidenza, libertà, ontologismo, storia ideal eterna, De Antiquissima, A. Sabetta.

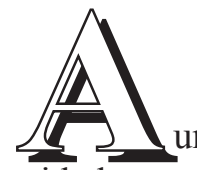

un siendo, sin duda, el filósofo italiano más significativo de la modernidad post-renacentista, Vico no es conocido o estudiado adecuadamente en los currículos filosóficos de los liceos italianos, tanto que, a menudo, todo su pen-

Este artículo responde a una invitación expresa por parte de la Dirección de la Revista para este volumen especial por el $350^{\circ}$ Aniversario del nacimiento de G. Vico, habiendo superado los criterios de valoración y del proceso de aceptación. 
samiento se reduce al eslogan efectista de los "corsi e ricorsi storici", y se acaba ignorando la instancia profunda y las características de su reflexión especulativa. Estudiando la relación entre cristianismo y modernidad en un intento de superar una tesis historiográficamente difundida acerca de la alternancia entre los dos, me enfrenté con la postura del filósofo turinés Augusto Del Noce, ${ }^{1}$ que, analizando el ateísmo como resultado último del racionalismo moderno, pone en cuestión la tesis de una única modernidad racionalista por las soluciones ateas (de Descartes a Nietszche) preguntándose si en el seno de la modernidad se podría encontrar una línea de pensamiento "otra", que se centrara y desarrollara precisamente de forma alternativa a la opción atea del racionalismo, recuperando un pensamiento de la trascendencia. Según Del Noce existiría una filosofía moderna irreductible al racionalismo y representada por el ontologismo, esa línea moderna de pensamiento de Descartes a Rosmini que ha permitido una reflexión y una afinación de las cuestiones metafísicas y comprendería a autores como el mismo Descartes, Pascal, Malebranche, Vico, Rosmini. Según Del Noce el pensamiento de Vico

«es la continuación de la crítica cartesiana del ateísmo tras haber criticado semejante concesión en la oposición a los libertinos que es el tratamiento propio de la ahistoricidad cartesiana, y la razón por la cual la crisis de la recepción cartesiana contra la irreligiosidad se manifiesta en el pensamiento de Bayle».2

Me puse entonces a la tarea de intentar comprender a este filósofo singular que, desde cualquier perspectiva en que se le quiera leer, representaba un nudo significativo, un pasaje obligado para entender el sentido y las formas de la modernidad. Empecé intentando verificar y estudiar la presencia de fuentes cristianas en Vico; cierta historiografía había sostenido siempre la relación entre Agustín de Hipona y Vico, además de entre Escoto y Vico, idea alimentada por algunos conocidos pasajes de la Autobiografía, y así nació un libro mío en el cual me adentraba en una excavación de las Oraciones inaugurales, del De Antiquissima y de las Obras jurídicas. ${ }^{3}$

La monografía que publiqué buscaba analogías o similitudes en el ámbito de la historia de las ideas que permitiesen reencontrar una vena cristiana en la inspiración del pensamiento viquiano, tratando de verificar además cuánto habrían impactado realmente la perspectiva de Agustín de Hipona o la filosofía de Escoto o de Suárez en la determinación de los senderos especulativos de Vico. Creo que se pueden reco-

1. Cfr. su obra teóricamente más significativa: Il problema dell'ateismo, Il Mulino, Bolonia, 1964.

2. Ibíd., pp. 480-481.

3. Cfr. A. SABetTA, I "lumi del cristianesimo". Fonti teologiche nell'opera di G.B. Vico, LUP, Roma, 2006, y el artículo «Fuentes cristianas del De Antiquissima Italorum Sapientia», Cuadernos Sobre Vico, n. 19-20, 2006-2007, pp. 73-118. 
nocer raíces, resonancias, pero la idea de la cual estoy cada vez más convencido es la de la irreductibilidad de Vico a una interpretación demasiado rígida y monolítica, porque su pensamiento se presenta así rico, compuesto y variado como para huir de toda reconducción dentro de estrecheces historiográficas fijas. En tal sentido, con motivo de esta riqueza, por ciertas cosas se podría aplicar a Vico lo que Habermas decía de Nietszche, o sea, el ser una "plataforma giratoria", ${ }^{4}$ y no es casual que, desde visiones muy diversas cuando no opuestas, se hayan efectuado reclamaciones, afiliaciones o reivindicaciones de derivaciones hacia el pensamiento viquiano.

Creo que hay que reconocer un dato: por un lado, Vico es un moderno; por otro lado, es expresión de una modernidad "distinta" y, en este sentido, puede ser considerado un segundo iniciador de la modernidad más allá de y contra Descartes. El pensador francés estaba preocupado (casi obsesionado) por la búsqueda de esa certeza inexpugnable capaz de vencer el escepticismo libertino y de garantizar un conocimiento verdadero; y también Vico, en el De Antiquissima, se plantea la misma exigencia de vencer al escepticismo, aunque con instrumentos en las antípodas de Descartes. Pero sobre todo cambia radicalmente la postura respecto al objetivo metafísico común con Descartes, a saber, la verdad: Vico, en efecto, por retomar las palabras de un autor que muy recientemente ha afrontado el sentido de la modernidad, para alcanzar la verdad describe un camino distinto, que pasa por la recuperación de lo que Descartes había apartado. Si Descartes pretende buscar

«una verdad eterna no fundamentada sobre la historia, y manteniendo a la retórica como algo extrínseco a tal verdad, Vico quiere afianzar el nexo que transcurre entre el estudio de las formas fantásticas, históricas y retóricas del pensamiento: Descartes, a su parecer, no acepta ni la relación entre hecho y verdad, ni el vínculo de la mente consigo misma. El rechazo de la retórica conduce a un razonamiento perverso, que confunde el verum con el certum, la ciencia con la consciencia». ${ }^{5}$

Por eso Vico es un filósofo singular, irreductible a los cánones historiográficos a menudo abanderados como exhaustivos en la interpretación de la modernidad; su ser diversamente moderno es otra cosa muy distinta de ser "antimoderno", pero explica la necesidad más allá de Vico, y a partir de Vico, de una revisión historiográfica de los paradigmas interpretativos de la modernidad.

La extraordinaria fascinación ejercida por el filósofo napolitano me ha impulsado a interrogar más de cerca la Ciencia nueva y a enfrentarme al laberinto de las interpretaciones de su pensamiento rico y a veces arduo. ${ }^{6}$ Ha sido, por tanto,

4. Cfr. la cuarta lección de Il discorso filosofico della modernità. Dodici lezioni, ed. it., Laterza, Roma-Bari, 1987, pp. 86-108.

5. E. Franzini, Moderno e postmoderno. Un bilancio, R. Cortina, Milán, 2018, p. 27. 
inevitable dar mi opinión sobre el tema más controvertido y rico, el de la providencia, releída en el seno de una sustancial continuidad del pensamiento viquiano (que no significa ausencia de evolución ni revueltas) y de la idea de que el principio del verum-factum mantiene el presupuesto necesario para entender también el sentido viquiano de la historia.

La idea que he intentado desarrollar es la de recobrar una "teología filosófica" en la Ciencia nueva. En cuanto el conocimiento de la historia es realmente científico gracias al principio del verum-factum (como lo era la matemática en el De Antiquissima), entonces puede tener pretensión de validez el discurso acerca de Dios, basado no sobre la naturaleza, sino sobre la historia. Mientras la teología "física" permanece últimamente incierta porque incierto es el conocimiento de lo físico (solo Dios conoce lo natural porque es su único autor), desde el momento en que no es posible el ideal del conocimiento como facere (sino solo como tenere genus), en cuanto no se puede "probar por su causa", por el contrario, en el caso de la historia, el conocimiento, el saber, es paradigmático, ejemplar. Así, la historia, desde el lugar por excelencia de lo accidental, de lo contingente y de lo arbitrario, se convierte por el contrario en el lugar donde se revela la verdad eterna, mucho más que la naturaleza, desde siempre añadida a la tarea de encontrar dicha verdad. ${ }^{7}$

El mundo de la historia, la innumerable sociedad de las costumbres de las naciones, ofrece las pruebas más sublimes, luminosas y distintas de Dios y de su providencia. Mirando a la naturaleza, al fin, contemplando la belleza del orden como expresión de la sabiduría eterna, y reflejándose sobre posibles destinos diversos de los acontecimientos, nos damos cuenta de la eterna bondad de Dios y descubrimos cómo el mundo "pende" de la omnipotente, sabia y benigna voluntad del Dios Óptimo Máximo.

En cuanto al mundo civil, en él se manifiesta Dios, pero es obra del hombre, a través del «severo análisis de los pensamientos humanos en torno a las humanas necesidades de la vida sociable» (que son las dos fuentes del derecho natural ius gentium), la ciencia nueva se convierte también en historia de las ideas humanas sobre la cual debe constituirse la metafísica de la mente humana; dicha ciencia describe una historia ideal eterna (fórmula casi oximórica) sobre la cual (es decir, teniéndola como fundamento y referencia normativa) discurren en el tiempo las historias de todas las naciones en todas sus fases -inicios, progreso, estabilidad, decadencia y fin (cfr. SN44, § 349)-.

6. De aquí mi segunda monografía sobre Vico titulada Vico. Metafisica e storia, Studium, Roma, 2011; precedida del ensayo «La storia tra provvidenza e libertà. La teología filosofica della Scienza nuova di G.B. Vico», Rassegna di Teologia, n. 50, 2009, pp. 559-590.

7. Cfr. P. Piovani, «Vico e la filosofia senza natura», en ID., La filosofia nuova di Vico, a cargo de F. TeSsitore, Morano, Nápoles, 1990, pp. 58; 70-71; 84-85. Este ensayo de Piovani sigue siendo una piedra miliar en los estudios viquianos. 
La historia ideal eterna se delinea, por tanto, no como una ley apriorística deducida por el sujeto, sino como una ley recabada desde el dato positivo de la historia, aceptado filológicamente, que indica la "forma" de los eventos y, como tal, define también una suerte de ley evolutiva, en consideración de cuanto Vico escribe en el parágrafo conclusivo de la Ciencia nueva, donde se refiere a la «historia ideal de las leyes eternas».

Lo dicho nos permite añadir que la Providencia es como el "director" de la historia, cuyos autores, los hombres, construyen sus partes sobre un cañamazo ya escrito, para, por un lado, convertir la historia en una obra propiamente humana, y por otro lado impedir que el curso de las naciones y los destinos de la historia misma sean abandonados a una causalidad irracional. ${ }^{8}$

No solo existe un diseño providencial, sino que este diseño es bueno: la Providencia, en efecto, es la manifestación, en el plano de las criaturas (cósmico y antropológico), de la identidad de Dios como bondad atenta que, de forma inteligente (él es "todo mente"), es decir, dentro de un diseño (la historia ideal eterna), se relaciona con la creación y la hace permanecer y tender hacia su significado que está "en riesgo", porque el fin de lo real, en cuanto implica la libertad del hombre, se expone al riesgo concreto de su negación, como la historia atestigua y documenta. Y también cuando las circunstancias impiden vivir según la rectitud de la buena intención, no por esto el hombre es abandonado a sí mismo; también en el caso extremo en el que la historia retrocediera radicalmente (la "barbarie de la reflexión", mucho más dramática que la "barbarie del sentido"), tal decadencia no representaría nunca el último estadio de la historia, y por ello traición y derrota de la providencia, sino el "fondo" desde el cual el hombre puede volver a partir y reencontrar el orden eterno de Dios mediante la piedad, la fe y la verdad.

Aquí encuentra pleno sentido, a mi entender, la dialéctica del curso y recurso. Siendo hecho el mundo civil de las naciones por los hombres, como verdaderos autores de la historia y no como "marionetas" guiadas por la Razón universal (sea cual sea el sentido que se le quiera atribuir a esta última), siempre está amenazado por la posibilidad de que el hombre, puesto que es libre, se distraiga del orden y en vez de seguirlo persiga caminos diversos que lo conduzcan hacia la mentira y la destrucción; sin embargo, ya que la realidad creada está también insuperablemente dentro de un diseño del bien, es Dios mismo, en cuanto providencia, quien garantiza el bien del hombre no tanto de forma extraordinaria y "puntual", a través de milagrosas intervenciones desde el exterior, sino ordinariamente, haciendo que incluso de la negación racional del fin (vagabundeo ferino y soledad bestial) resurjan aquellas virtudes que reconducen hacia el reconocimiento y el seguimiento del diseño providencial.

8. En el capítulo V de la "Política poética", titulado «Che la divina provvidenza è l'ordinatrice delle repubbliche e nello stesso tempo del diritto naturale delle genti» (cfr. §§ 629-633), Vico recorre esta "dirección" de la providencia en las diversas etapas de la historia. 
Esta visión y afirmación de la invencibilidad última de la providencia, como artífice de la estructura ideal eterna de la contingencia histórica, viene confirmada además (y, añado, sobre todo) por la experiencia humana de Vico. Además de la carta al padre Giacco del 25 de octubre de 1725, que acompaña a la copia de la primera Ciencia nueva, toda la Autobiografía no es más que recorrer momentos y acontecimientos de su vida y, a posteriori, reconocer en ellos el diseño benévolo de la providencia. Así, la experiencia humana de Vico se convierte en un caso único e ilustrativo de esa historia ideal eterna científicamente reconstruida en la Ciencia nueva como teología civil razonada de la providencia.

En este horizonte se sitúa la heterogénesis de los fines, o sea el hecho, como leemos en la conclusión de la Ciencia nueva, de que si bien el mundo (histórico) ha sido hecho por los hombres, sucede, sin embargo, que ese mundo se configura y toma direcciones totalmente contrarias y siempre superiores a los fines particulares, a las intenciones y a los propósitos concretos de los hombres (cfr. § 1.008). Una heterogénesis de los fines, podríamos decir, oportuna y "mejoradora", desde el momento en que la diferencia entre realidad e intentos, y la irreductibilidad, si no la oposición, entre hechos y propósitos es tal que el curso de los eventos, o sea, la determinación del sentido de la historia como urdimbre sostenedora de las mallas tejidas en el transcurso de las épocas, manifiesta una positividad mayor que la intencional de los hombres, incluso impensable, ya que a menudo es contraria a los presupuestos y a las intenciones (cfr. $S N 25,45$ ).

Vico explica esta dinámica de la historia, reconducible a la providencia, con una anáfora que en seis momentos muestra, según una progresiva ampliación del horizonte, cómo de la lujuria bestial nacen los matrimonios castos, de los imperios de los padres sobre los clientes las ciudades, del abuso de la libertad señorial sobre los plebeyos la libertad popular, del deseo de los pueblos libres de desvincularse del freno de las leyes acaban naciendo las monarquías, del envilecimiento de los súbditos por obra de los vicios de los monarcas se deriva la esclavitud y, finalmente, en el tiempo de la decadencia, de la dispersión de las naciones como un ave fénix nuevamente las naciones que se reconstituyen (cfr. § 1.108).

Este dato, de hecho, inevitablemente entreabre la posibilidad de una interpretación en términos crocianos y neoidealistas, que reconduce la providencia a la figura hegeliana de la astucia de la razón, pero podría casarse también con la idea cristiana, compartida por Vico, en base a la cual el hombre histórico está atravesado por una debilidad radical que, tanto en el plano del intelecto como en el de la voluntad, le impide, o le hace extremadamente problemático, el pensar y sobre todo el actuar siguiendo el bien propio y el de la sociedad. En otras palabras, el dato fundamental del pecado original, sobre todo en el sentido de una acrecentada incapacidad para vivir según el fin propio y la verdad, dispone al hombre hacia comportamientos en el transcurso de la historia que, sin una intervención divina, conducirían 
a la humanidad por senderos distintos del bien y del fin en vista de los cuales Dios ha creado el universo y al hombre. Por tanto, la providencia en el plano natural, o inmanente, se convierte en la forma con la que Dios interviene para proveer a la objetiva e histórica debilidad del hombre, haciendo que, no obstante dicha debilidad, el actuar histórico no impida la realización de ese diseño eterno que constituye el bien del hombre en cuanto directamente querido por Dios.

Y Dios lo hace no contra la voluntad del hombre, sino determinando un propósito distinto al amor hacia la utilidad propia, aunque conservando dicho amor. El amor propio es lo que tiraniza al hombre a causa de su corrompida naturaleza y lo empuja a buscar «todo lo útil para sí, y nada para el compañero» $(S N 30,128)$, impidiendo así que el conato ponga freno a los movimientos impresos en la mente por el cuerpo, ya sea en la dirección de la sabiduría (como "apaciguamiento" de dichos movimientos) o en la de la virtud civil (que dirige dichos movimientos hacia la justicia). La providencia, por el contrario, como divina mente legisladora, transforma las pasiones del hombre -que, si se abandonaran a sí mismas, lo conducirían a una condición bestial de soledad - en fuerza ordenada, justamente, hacia el orden y la sociedad. ${ }^{9}$

La cuestión decisiva resulta ser, entonces, la relación entre la providencia y la libertad humana. La providencia resta transcendencia inmanente en cuanto irreductible a los deseos y a los proyectos humanos (por eso es transcendente), pero al mismo tiempo operante en la historia de los hombres (y por consiguiente inmanente), lo cual imprime un orden no de luz extrínseca al actuar del hombre mismo; por otro lado, la libertad conserva su total autonomía, desde el momento en que Dios no se sustituye en el actuar del hombre, sino que simplemente imprime a dicha libertad cierta dirección, porque, en cuanto providencia, se mantiene como arquitecta y ordenadora del mundo de las naciones gracias (y no obstante) a la libertad humana en la búsqueda de lo útil y lo necesario.

Ciertamente, una providencia tan presente e "invasiva", como ley de la historia, ¿hasta qué punto puede ser compatible con la idea de que la historia la hacen los hombres y, por tanto, con la libertad? Creo que el capítulo V del De Antiquissima y el planteamiento de la relación entre gracia y libertad ayudan a comprender la dialéctica en el plano histórico entre providencia y libertad, sin que el hombre deje de ser libre y sin que dicha libertad pueda nunca comprometer el sentido de la historia que el hombre no puede constituir. Donde hay libertad existe siempre el riesgo de alejarse de la verdad y del bien y así ha acaecido en la historia, cuando la libertad ha postrado a la humanidad en esa condición ferina de la que el hombre ha sido ayudado por Dios a levantarse de nuevo, y cada vez que el hombre es tentado y expuesto al riesgo de pervertir el sentido de las cosas y de la historia, Dios-providencia lo

9. Cfr. Dignidad VII (§ 133). 
acompaña, impidiendo que el hombre destruya su humanidad y haciéndolo reencontrar lo verdadero incluso mediante una heterogénesis de los fines de la que está empapada la dinámica histórica. Y puesto que el hombre Deum aspectu amittere omnino non potest, no sucederá nunca que por la siempre posible involución él no pueda volver más a la condición "humana", siendo garante de ello Dios mismo, lo que revela que la libertad se debilita, sí, pero nunca se cancela.

Otras lecturas e interpretaciones de la providencia y de la relación entre libertad y providencia son posibles, la que he esbozado brevemente me parece plausible a la luz del recorrido viquiano. En la parábola humana y de pensamiento (tan profundamente entrelazados) en Vico no puede ser descuidado o minimizado el papel de la tradición cristiana, sobre todo la referencia a Agustín de Hipona y a su moderno restablecimiento; un restablecimiento que estaba talmente alejado de la pusilánime teología contemporánea a Vico, como para despertar más sospechas que aceptaciones, puesto que la normatividad y la fidelidad servil al dato bíblico en su literalidad, incluso respecto a lo que la Biblia no quería enseñar ciertamente con certeza, era el único criterio para un pensamiento (si todavía se puede llamar tal) posible y "ortodoxo".

Que Vico intentase cubrir con referencias exteriores a la tradición cristiana un pensamiento heterodoxo para evitar censuras y condenas me parece inadmisible; que Vico todo el camino no percibiese los "riesgos" heterodoxos de su pensamiento no puede excluirse en absoluto. Se mantiene, sin embargo, aquella afirmación conclusiva de la Ciencia nueva: «si no se es piadoso, no se puede de veras ser sabio» (§ 1.112), ${ }^{10}$ para recordar que sin piedad, sin religión, el hombre está postrado en la barbarie de la ferinidad, aquella religión que no es alternativa a la religión revelada pero es la forma del comunicarse de Dios en los acontecimientos humanos, o sea, la providencia que, sin interrumpir nunca la libertad, sostiene al hombre en la historia para que no se extravíe definitivamente y para que realice el diseño en el que providencia y libertad concurren conjuntamente.

[Trad. del italiano por María José Rebollo Espinosa]

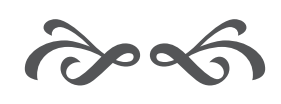

10. Palabras que recuerdan el Salmo 110: initium sapientiae timor Domini. 